\title{
Metacognitive Idea on Hypermnesia
}

\section{Omer Kose, Cekdar Aytimur}

\section{Background}

- Flavell (1979) has made the definition of metacognition which is 'thoughts about thoughts'.

- Metacognition is often expressed as confidence judgements regarding what we know (Lofthus, Wagenaar, 1988).

- Payne (1986) defined hypermnesia as the increase in the number of item recalled by repeated tests or retention interval.

- People's predictions towards future events are not always correct. They can overestimate or underestimate their performance on a given task due to their emotional reactions (Wilson, Gilbert, 2005).

- Although there are sufficient research in the field of metacognition and hypermnesia seperately, metacognition has not focused on hypermnesia.

\section{Hypothesis}

- People would overestimate their performance in both image and word tasks and monetary incentives enhances their memory consolidation.

\section{Method}

\section{Participants}

- 134 undergraduate student were recruited from the Department of Psychology of Bingol University, Turkey.

\section{Design}

- Participants were randomly allocated to conditions, 2 (forecast: prediction vs. performance) $\mathrm{X} 2$ (recall type: image vs. word) $\mathrm{X}$ 2(incentive vs. no-incentive), manipulated between subjects.

\section{Experimental Task}

- 80 neutral images and words on different conditions were shown to the participants.

\section{Procedure}

- Participants were illustrated 80 images or 80 words within the sequence of a second. Then, participants were told to write as many as images or words down in a period of 3 minutes. When the time is over participants faced the same 80 images or words.

- In the prediction condition participants performed the task 3 times and made judgements about their actual performance if they perform the task 10 times in total. In the performance condition participants performed the task at 10 trials without making any judgement.

- Incentives were applied as an independent variable. Participants in the incentive condition were asked that how many words or images they would recall if they perform the task 10 times and earn money for the each item recalled. Also participants were told that they would earn some monetary rewards at the end of the 10th trial. Participants in the no-incentive condition were not mentioned about monetary incentives.

\section{Results}

- 3-Way interaction was found between forecast, recall type, and incentive: $F(1,124)=3.82, p<0.5$.

- 2-Way ANOVA results revealed that there was a statistically significant interaction between recall type and incentive in the participants' performance but not in the prediction (see figure 1), $F(1,60)=3.99, p<$ 0.5 and $F(1,64)=.882 \mathrm{p}>0.5$, respectively.

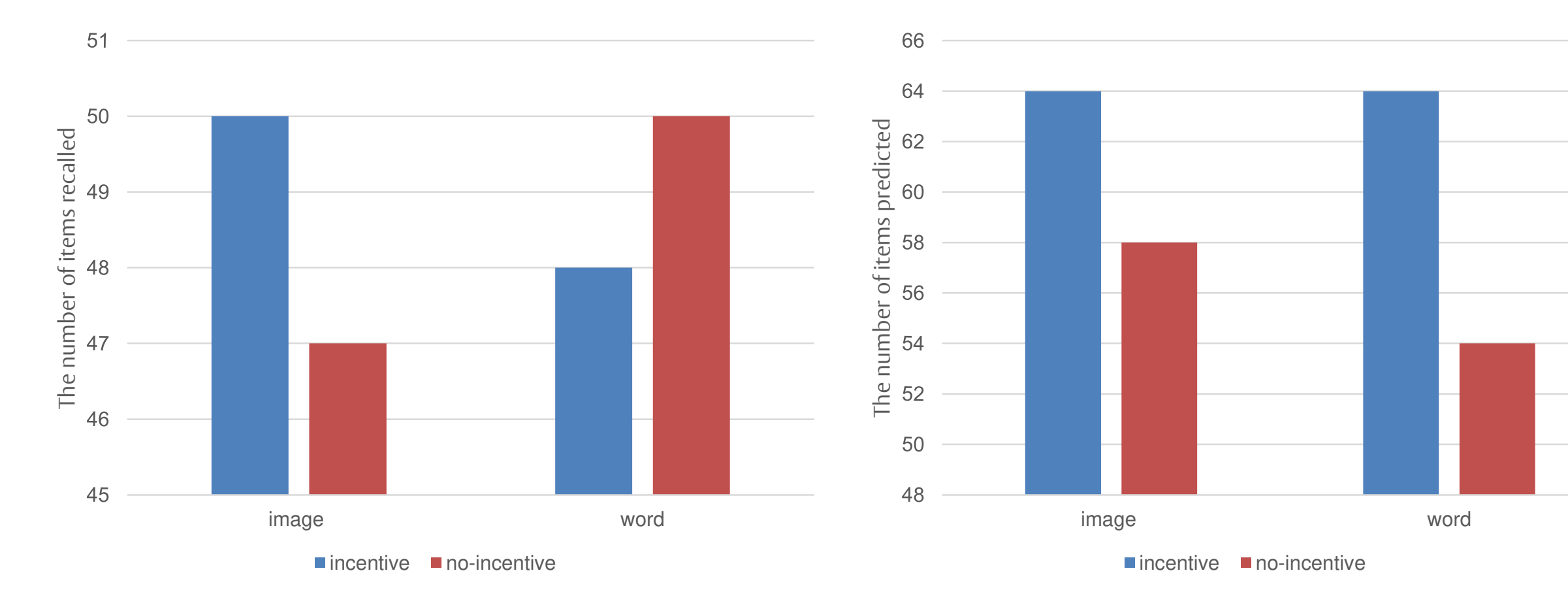

Figure 1: The number of items recalled and predicted by participants through the experiment.

- Cumulative number of the recalled items shows that hypermnesia was obtained most of the time (see figure 2 ).

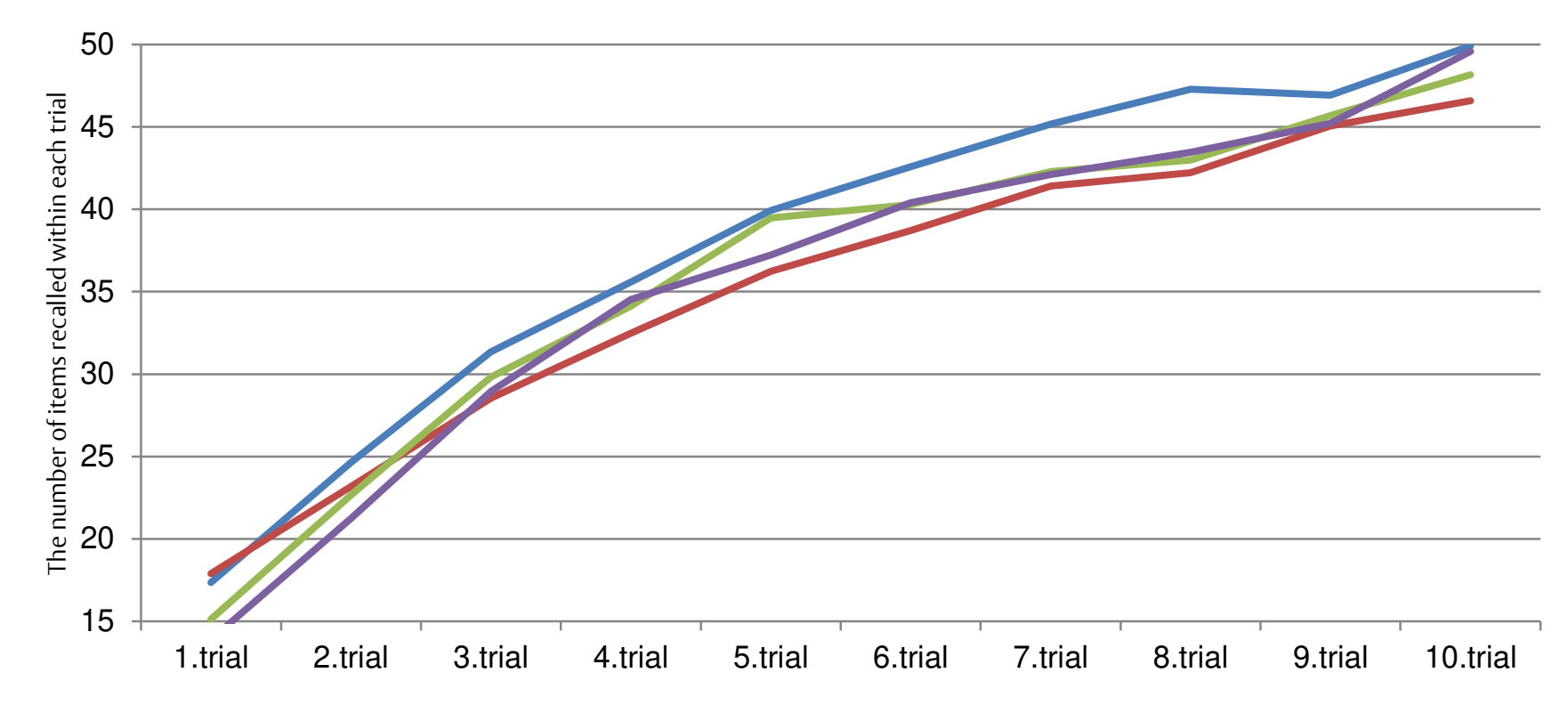

Figure 2: The cumulative number of each trial among conditions.

\section{Discussion}

- People overestimated their performance during the word task but not image task.

- When people predicted their performance on the image and word task, monetary incentives did not work as much as their actual performance on the image and word task.

- Hypermnesia was obtained properly until the 5th and 6th trial, then the efficacy of repetition was slowing down.

\footnotetext{
References

1. Flavell, J. H. (1979). Metacognition and cognitive monitoring: A new area of cognitive-developmental inquiry. American Psychologist, 34(10), 906.

2. Loftus, E. F., \& Wagenaar, W. A. (1988). Lawyers' predictions of success. Jurimetrics, 437-453.

3. Payne, D. G. (1986). Hypermnesia for pictures and words: Testing the recall level hypothesis. Journal of Experimental Psychology: Learning, Memory and Cognition, 12(1), 16.

4. Wilson, T. D., \& Gilbert, D. T. (2005). Affective forecasting knowing what to want. Current Directions in Psychological Science, 14(3), 131-134.
} 